\section{BC walk-in clinics warned}

$\mathrm{D}$ octors at walk-in clinics must deliver the same quality of patient care as in other settings, the BC College of Physicians and Surgeons has warned members.

The unusually strong reprimand issued in the college's quarterly newsletter cites a long litany of problems at some walk-in clinics, including doctors failing to follow-up patients, test results, diagnoses and treatment; failing to send visit summaries to the patient's primary care physician (if there is one); and failing to ensure availability after-hours.

The college also issued guidelines for patient record-keeping at clinics, while requiring them to treat patients who come in "on 3 or more occasions for similar or related complaints, particularly in the absence of an identified family physician," as if they are the primary care provider.

The stern warning was the result of "a series of complaints over a long period of time," coming from both patients and primary care physicians, College Deputy Registrar Dr. Doug Blackman told CMAJ.

When informed of the complaints, physicians would invariably plead that it wasn't their responsibility, said Blackman. "As often as not a physician would say, 'yes, I didn't do such and such - but I only work at a walk-in clinic,' or, 'yes, the patient was really sick - but we only work at a walk-in clinic.' That wasn't an excuse."

"I don't know that anybody's died, but we as a college ... aren't waiting until somebody dies until we respond," added Blackman. Like its counterpart in Alberta, the college was especially critical of the practice of restricting patients to "I complaint per visit," and argued that walk-in clinics should be considered the primary care providers for patients who visit 3 times.

But BC Medical Association President Margaret MacDiarmid says some patients use walk-in clinics near their workplace, while having a primary care physician near their home. In such instances, she said, no one wants the walk-in facility designated for their primary care.

A college reprimand may make the job of finding a family doctor more dif- ficult, MacDiarmid said, adding that many family physicians felt "attacked" by the college's missive. "It's good we have constructive ideas from our regulatory body, but we should ensure that we don't make the job so difficult, nobody wants to do it." - Deborah Jones, Vancouver, BC

DOI:Io.I503/cmaj.o6r484

\section{Quebec specialists with-}

\section{draw teaching services}

M edical students fear their training is being compromised by the latest pressure tactic from the Quebec Federation of Medical Specialists (QFMS) in its continuing dispute with the provincial government over controversial Bill 37 .

The QFMS counselled members to suspend all activities for which they're not paid - including teaching duties - in an effort to force the government to rescind the bill, which imposed a pay settlement and working conditions on Quebec's 8000 medical specialists until 2010 (CMAJ 2006;175[II]:86I).

"It's one of the only means we have to show our anger," says QFMS VicePresident Dr. Louis Morazain. "Of course, students are suffering the collateral effects of that."

Thus far, the brunt has been borne by first- and second-year medical students at l'Université de Montréal. Only 2 specialists showed up Oct. 24 to supervise 30 first-year students in interactive tutorials. The normal ratio is 4:I.

"The hospital told us not to come back," says Josée Larochelle, vice-president of external affairs for the Quebec Federation of Medical Students. Onethird of students are "missing out on that real-life training."

Faculty and students have since worked out a compromise: second-year students facing exams are given priority access to the few specialists defying the QFMS edict, while first-year students are receiving condensed lectures.

Morazain believes most students "understand" that the protest measure is in their long-term professional interest, but
Larochelle finds that patronizing. "Why can't we decide what's good for us?"

A similar withdrawal of services in 2002-03 resulted in the students unsuccessfully seeking an injunction against the specialists. With no legal redress now available, Larochelle fears the current dispute will drag on indefinitely. "This is being imposed on us and we have no recourse except to complain. We are absolutely caught in the middle."-Loreen Pindera, Montréal

Loreen Pindera is a reporter for CBC RadioMontréal.

DOI:Io.I503/cmaj.06I474

\section{News@ a glance}

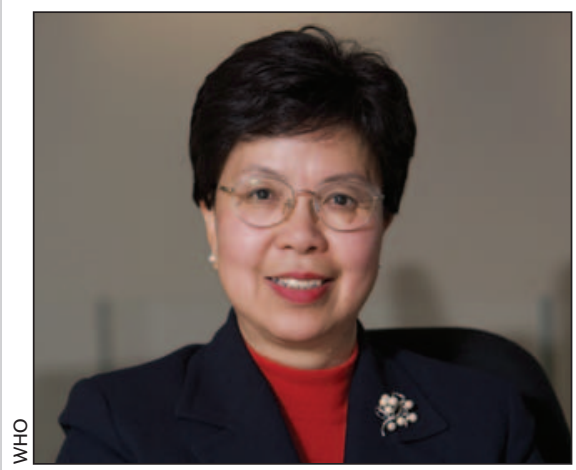

New WHO Director-General: Dr. Margaret Chan, from the People's Republic of China, will become the new WHO Director-General on Jan. 4. Chan, who obtained her medical degree from the University of Western Ontario, vows to focus WHO's attention on Africans and women around the world. Chan was most recently WHO's director of Communicable Diseases Surveillance and Response, and Representative of the Director-General for Pandemic Influenza. She succeeds Dr. Jong-Wook Lee who died May 22.

Lam wins Giller: Dr. Vincent Lam's debut work of fiction, Bloodletting and Miraculous Cures, (CMAJ 2006: I74[5]:665-6) won the $\$ 40$ ooo Giller Prize Nov. 7. Lam, 32 and an emergency department physician in Toronto also inked a deal to convert the book into a TV series. — Barbara Sibbald, CMAJ

DOI:Io.I503/cmaj:061462 